
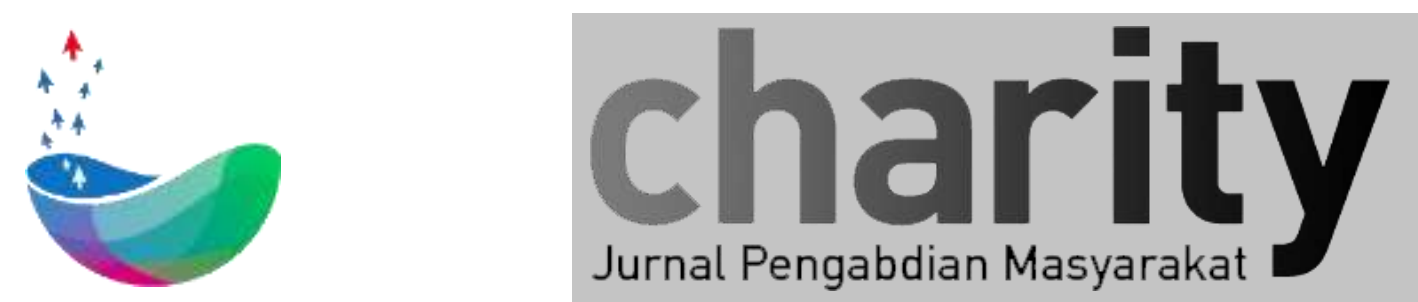

\title{
OPTIMALISASI USER INTERFACE PORTAL PESONA GARUT UNTUK PENINGKATAN PARIWISATA DAN PEREKONOMIAN MASYARAKAT KABUPATEN GARUT
}

Arief Budiman ${ }^{1}$, Fhira Nhita ${ }^{2}$, Adiwijaya ${ }^{3}$, Indra Lukmana Sardi ${ }^{4}$, Dawam Dwi Jatmiko ${ }^{5}$, Novian Denny Nugraha ${ }^{6}$, Sakina Fathiani ${ }^{7}$

${ }^{1}$ Fakultas Industri Kreatif, Instistusi, Universitas Telkom ${ }^{2}$ Fakultas Informatika, Instistusi, Universitas Telkom

Fakultas Informatika, Instistusi, Universitas Telkom

${ }^{4}$ Fakultas Informatika, Instistusi, Universitas Telkom

${ }^{5}$ Fakultas Informatika, Instistusi, Universitas Telkom

${ }^{6}$ Fakultas Industri Kreatif, Instistusi, Universitas Telkom

${ }^{7}$ Fakultas Industri Kreatif, Instistusi, Universitas Telkom

*ariefiink@telkomuniversity.ac.id, fhiranhita@telkomuniversity.ac.id

\section{INFO ARTIKEL}

Diterima 20 Juni 2019

Direvisi 27 Juni 2019

Disetujui 30 Agustus 2019

Tersedia Online 09 September 2019

\begin{abstract}
ABSTRAK
Banyaknya potensi wisata yang terdapat di Kabupaten Garut memicu munculnya banyak keinginan dari wisatawan untuk mendapatkan informasi yang lengkap mengenai pariwisata dan kekhasan lainnya dari Kabupaten Garut. Kebutuhan wisatawan adalah informasi yang akurat dan tepat mengenai tempat pariwisata, tempat menginap, produk atau jasa layanan yang ditawarkan di Kabupaten Garut khususnya bagi wisatawan muslim. Informasi wisata halal juga menjadi daya tarik yang besar khususnya untuk wisatawan muslim dalam dan luar negeri. Informasi tersebut dapat memuat informasi destinasi, penginapan, restoran halal yang memenuhi kriteria halal misalnya memiliki mesjid, mushola yang layak, tidak menjual alkohol dan kriteria halal lainnya. Optimalisasi user interface menjadi perhatian khusus dengan memperhatikan aspek pendekatan kultural. Dengan hasil dari kegiatan tersebut diharapkan dapat lebih memberikan kenyamanan serta kemudahan kepada calon wisatawan dalam mendapatkan informasi yang dibutuhkan dan berimplikasi terhadap kemajuan pariwisata yang ada di Kabupaten Garut
\end{abstract}

Keyword: user interface, kabupaten garut, pariwisata

\author{
Korespondensi : \\ Direktorat Penelitian dan Pengabdian Masyarakat, Universitas Telkom \\ Jl. Telekomunikasi No. 1, Terusan Buah Batu, Bandung, 40257 Indonesia. \\ E-mail: charity@telkomuniversity.ac.id
}

ORCID ID: 0000-0002-7433-8667

Penulis Pertama: Arief Budiman

https://doi.org/10.25124/charity.v2i1.2034

Paper_reg_number 2034 @ The Authors. Published by Directorate of Research and Community Service, Telkom University.

This is an open access article under the CC BY-NC 4.0 license (https://creativecommons.org/licenses/ by-nc/4.0/) 


\section{PENDAHULUAN}

Website menjadi media yang cukup efektif dalam memberikan sebuah informasi yang dapat diakses oleh siapa pun, kapan pun, dan dimana pun. Pemanfaatannya sudah menjadi suatu hal yang berguna tentunya dalam berbagai macam kebutuhan. Perkembangan pariwisata pun tidak bisa lepas dari media tersebut, media website telah berperan cukup besar dalam meningkatkan kunjungan - kunjungan wiatawan ketempat yang akan mereka inginkan. Kabupaten Garut merupakan daerah pariwisata yang sangat banyak dikunjungi wisatawan setiap tahunnya. Tingginya jumlah pengunjung ke daerah pariwisita di Kabupaten Garut memicu munculnya banyak keinginan dari wisatawan untuk mendapatkan informasi yang lengkap mengenai pariwisata dan kekhasan lainnya dari Kabupaten Garut. Kebutuhan wisatawan adalah informasi yang akurat dan tepat mengenai tempat pariwisata, tempat menginap, produk atau jasa layanan yang ditawarkan di Kabupaten Garut khususnya bagi wisatawan muslim. Marketing berbasis teknologi informasi terutama teknologi yang memanfaatkan internet merupakan salah satu cara yang paling efektif dan efisien yang digunakan untuk melakukan promosi wisata. Informasi wisata halal juga menjadi daya tarik yang besar khususnya untuk wisatawan muslim dalam dan luar negeri. Informasi tersebut dapat memuat informasi destinasi, penginapan, restoran halal yang memenuhi kriteria halal misalnya memiliki mesjid, mushola yang layak, tidak menjual alkohol dan kriteria halal lainnya.

Kabupaten Garut termasuk salah satu destinasi unggulan pariwisata di Jawa Barat. Pantai selatan dan Cipanas merupakan salah satu destinasi favorit wisatawan berdasarkan data wisatawan tahun 2017 berikut ini. Dari data yang kami peroleh untuk tahun 2017 total wisatawan yaitu 2,378,990 dari 38 destinasi wisata, dengan jumlah wisatawan luar negeri sebanyak $0,24 \%$ dari total wisatawan. Dari data tersebut, jumlah wisatawan di Kab. Garut perlu ditingkatkan sehingga dibutuhkan media promosi yang lebih menarik, lengkap, dan akurat, khususnya untuk wisatawan luar negeri atau wisatawam muslim dalam/luar negeri. Dukungan Pemerintah Kab. Garut terhadap kerjasama program Pengabdian Masyarakat yang telah dijalani tahun 2017 dan 2018 ini sangat baik. Pada tahun 2017 kami telah melakukan serah terima portal wisata versi awal yang telah dibangun : http://visitgarut.garutkab.go.id/ kemudian tahun 2018 telah ditambahkan beberapa fitur yaitu dashboard wisatawan, pembuatan template bilingual, dan managemen admin yang memberikan akses kolaborasi bagi admin hotel, restoran, travel dan lainnya. Bentuk dari dukungan penuh Dinas Pariwisata dengan menjadikan Portal ini menjadi Portal tunggal domain go.id dan menyediakan admin khusus untuk mengelola web menjadi langkah baik dalam yang dapat bekerja sama dengan para GM hotel, resto, travel untuk berkolaborasi mengupdate konten di laman portal. Bahkan dukungan pun bukan hanya datang dari Dinas Pariwisata saja tetapi dukungan tersebut datang langsung dari Bapak Bupati Garut yang berharap tampilan dari website Portal Pesona Garut dapat berubah lebih baik agar dapat menarik lebih banyak wisatawan dalam negeri maupun luar negeri dan menjadi portal wisata halal percontohan bagi daerah lainnya.

\section{SOLUSI PENGABDIAN}

Solusi yang ditawarkan dalam mengoptimalisasikan media promosi pariwisata berupa website Portal Pesona Garut, dilakukan untuk dapat memberikan pembaharuan pada user interface agar dapat menyampaikan informasi kepada calon wisatawan lokal dan mancanegara dalam upaya meningkatkan pariwisata dan perekonomian masyarakat 
kabupaten Garut. Dalam optimalisasi tampilan user interface ada dua hal yang akan menjadi fokus perancangan, yakni dari aspek wireframe dan tampilan desain grafis.

\section{A. Wireframe}

Perancangan website ada baiknya terlebih dahulu menentukan rancangan wireframe yang menjadi tema acuan sebagai landasan dasar dalam konsep perancangannya. Wireframe merupakan kerangka dasar sebelum proses mendesain akan dimulai, dalam membangun rancangan wireframe hal yang harus diperhatikan adalah menentukan tampilan layout agar dapat diterima dengan baik oleh target audiens. Perancangan dengan mempertimbangkan layout, navigasi, dan komunikasi yang tepat akan mempengaruhi bagaimana proses development dapat terstruktur dan dapat mengarahkan informasi yang ingin disampaikan secara baik dan komunikatif. Pada optimalisasi website Portal Pesona Garut yang dapat dikatakan mempunyai cukup banyak content yang ingin disampaikan, maka perancangan akan mengedepankan aspek kemudahan bagi penguna dalam mendapatkan informasi yang dibutuhkan. Penentuan kerangka wireframe dengan mengunakan konsep portrait dengan cara scrolling ke bawah menjadi pilihan yang cukup logis yang akan digunakan.

\section{B. Desain Grafis}

Aspek desain grafis dalam hal ini menampilkan serta mengkomunikasikan sebuah konsep melalui citra visual. Hal tersebut menjadi cukup penting karena tangkapan pancaindra mata akan mempengaruhi citra dari sebuah media yang akan diterima oleh pengguna. Maka dalam perancangan desain grafis pada website Pornal Pesona Garut akan mengunakan pendekatan nuansa islami dan modern casual. Pendekatan tersebut yang nantinya akan digunakan untuk menghasilkan tipe visual yang akan digunakan dalam optimalisasi tampilan pada website Portal Pesona Garut.

\section{Islami}

Nuansa islami digunakan dari kota Garut itu sendiri yang memang mempunyai citra islami yang sudah cukup kuat. Selain itu nuansa islami digunakan untuk memperkuat dari tema besar website Portal Pesona Garut yang memang mempunyai target sasar bagi wisatawan muslim.

\section{Modern dan casual}

Kata modern diambil berdasarkan pertimbangan untuk mengubah positioning khususnya bagi website yang secara langsung ditangani oleh pemerintahan. Perubahan tersebut diharapkan dapat merubah citra agar mendapatkan perhatian khususnya dari wisatawan lokal maupun asing yang mencari informasi wisata melalui media website. Selain itu kesan modern lebih dapat memberikan nuansa kepercayaan terhadap informasi yang akan di akses oleh para wisatawan. Kesan casual (santai) diterapkan untuk memberikan kesan ringan dalam menyampaikan informasi tempat - tempat wisata yang dapat dikases oleh siapa pun dan dimana pun untuk mendapatkan tujuan terbaik dalam merencanakan wisata.

\section{REVERENSI WEBSITE WISATA}

\section{A. Layout}

Sumber gagas perancangan wireframe dalam hal layout website merujuk pada solusi yang telah dirumuskan sebelumnya. Dari referensi visual tersebut dapat terlihat tampilan pada menu utama lebih banyak didonimasi dengan foto - foto sedangkan posisi navigasi 
tidak terlalu banyak memakan ruang, hal tersebut dikarenkan dalam website wisata lebih banyak memperlihatkan keindahan dari tujuan wisata yang akan diinformasikan.

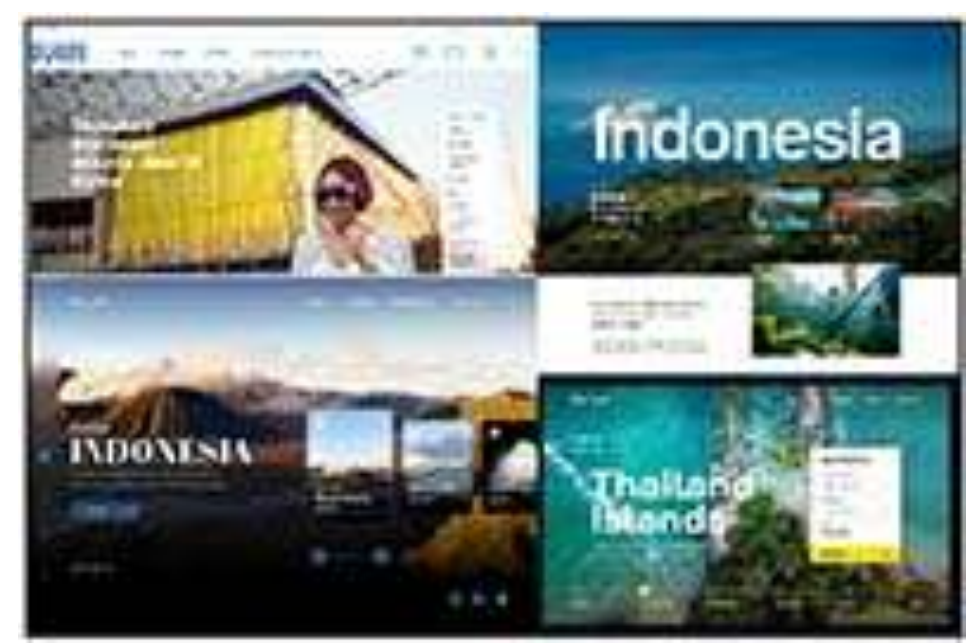

Gambar.1 referensi dalam layout.

(Sumber : berbagai sumber)

\section{B. Tipografi}

Sumber gagas dalam pengunaan typografi mengambil referensi dengan jenis hurus sans serif dengan pertimbangan agar nilai keterbacaan serta kesan casual yang ingin disampaikan dapat terakomodir dengan baik di dalam perancangan pengunaan dari sebuah typografi.

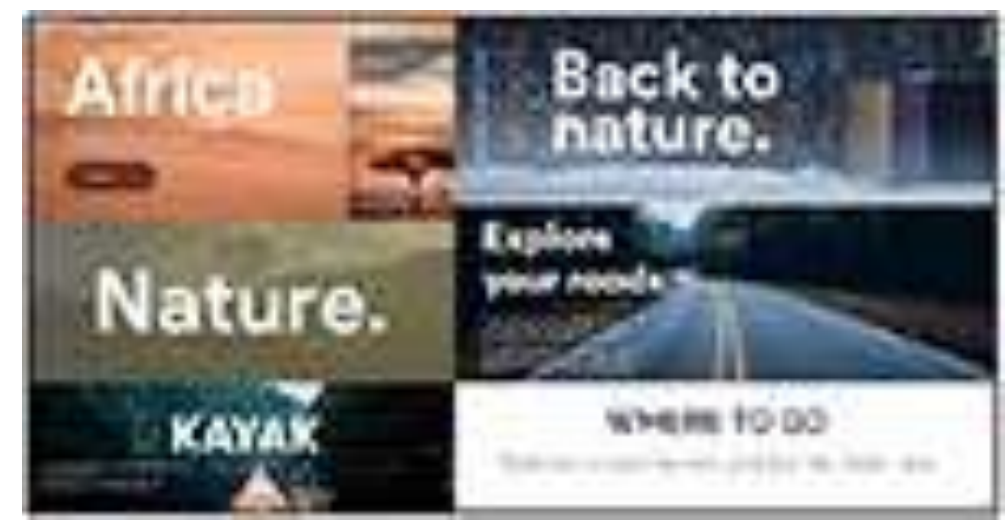

Gambar.2 referensi dalam typografi.

(Sumber : berbagai sumber)

\section{Ornamen Estetis}

Sumber gagas untuk perancangan ornament estetis mengambil jenis ornamental yang mengedepankan nuansa islami dengan mengambil beberapa referensi dari ornament ornament yang melekat pada masjid yang menjadi tempat ibadah bagi masyarakat muslim. 


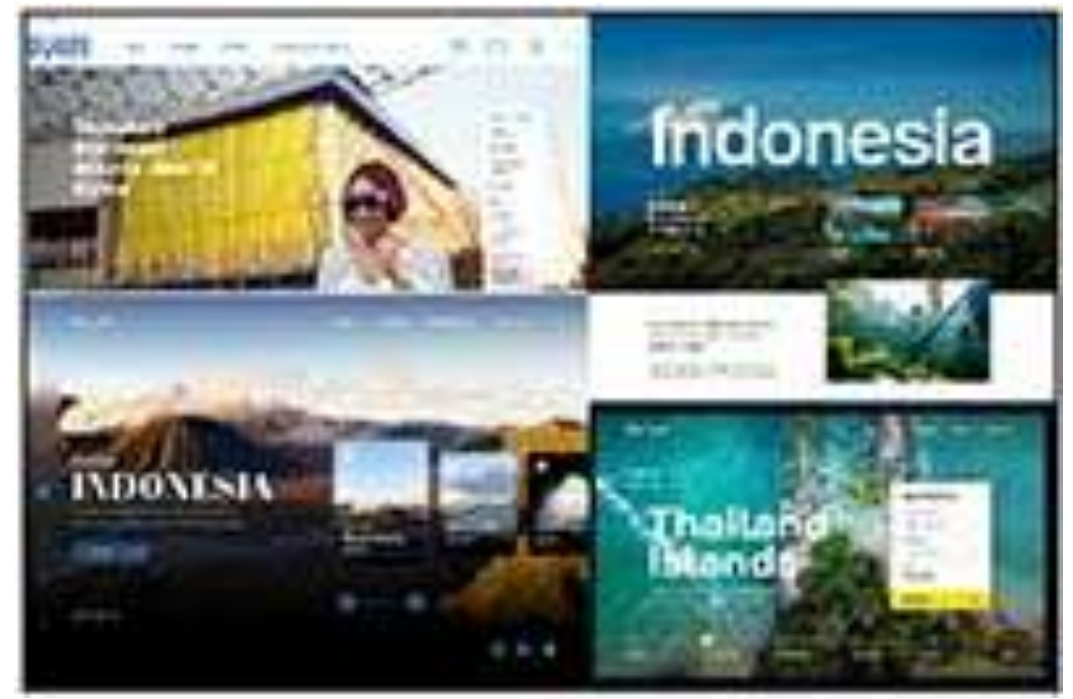

Gambar.3 referensi dalam ornamen estetis.

(Sumber : berbagai sumber)

Warna

Sumber gagas untuk menentukan warna, mengambil dengan pendekatan dari nuansa alam yang dimana Kota Garut memiliki pemandangan alam yang indah, dingin, dan sejuk maka nuansa pegunungan menjadi landasan reverensi.

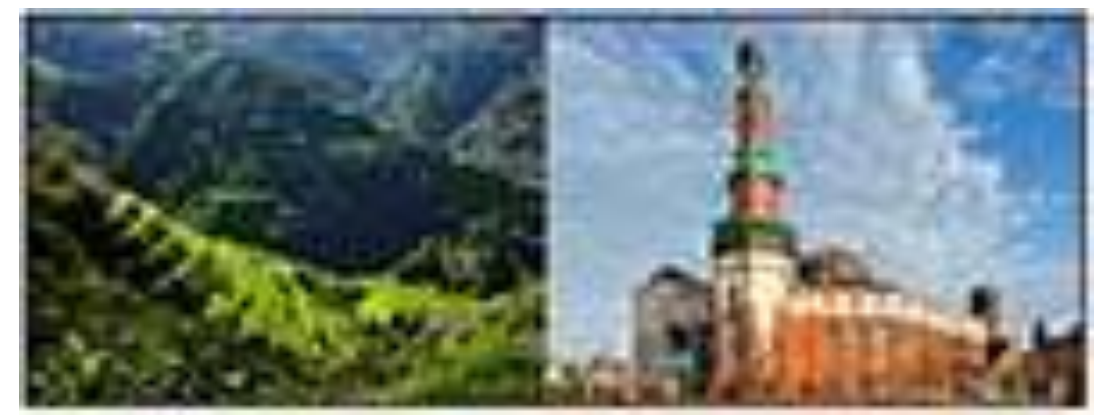

Gambar.4 referensi dalam ornamen estetis.

(Sumber : berbagai sumber)

\section{STUDI VISUAL}

\section{Warna}

Dalam menentukan warna yang akan diimplementasikan pada perancangan, perlu dilakukan studi color mood untuk mendapatkan kesan nuansa islami yang dirumuskan menjadi skema warna utama dan warna pendukung yang akan menjadi panduan dalam perancangan. Berikut adalah warna - warna yang akan diimplemantasikan dalam perancangan website Portal Pesona Garut. 


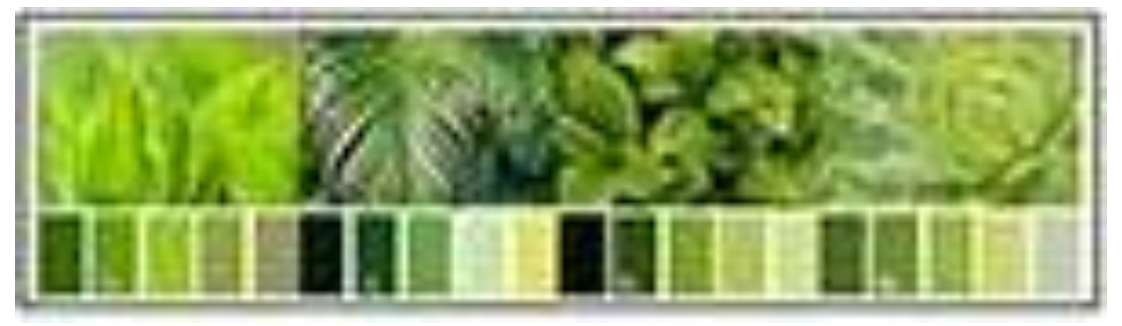

Gambar.5 studi warna.

(Sumber : berbagai sumber)

Pengunaan warna hijau dengan konsep skema warna analogus dapat mengidentikan terhadap 2 hal yang ingin dikomunikasikan. Pertama, pengunaan warna tersebut cukup dapat merepresentasikan dari citra nuansa yang berkesan islami. Sentuhan nilai islami yang tertuang dalam warna hijau tak luput dari keberadaan kota Garut sendiri yang menerapkan nilai keagamaan yang cukup kuat pada masyarakatnya. Sejalan dengan konsep tersebut penerapan warna hijau diperlukan dalam memperkuat citra yang akan ditawarkan dalam sebuah konsep besar dari Porta Pesona Garut yang memamang menawarkan positioning sebagai porta Halal Tourism. Kedua, penerapan warna hijua akan memperkuat nuansa dari keindahan nuansa alam yang natural dari kota Garut.

Sementara untuk citra casual dan modern akan muncul color mood yang bernuansa lebih segar dan lebih terang dan mempunyai komposisi warna yang lebih ringan dan tidak terlalu berat, berikut tampilan pilihan warna yang akan digunakan;

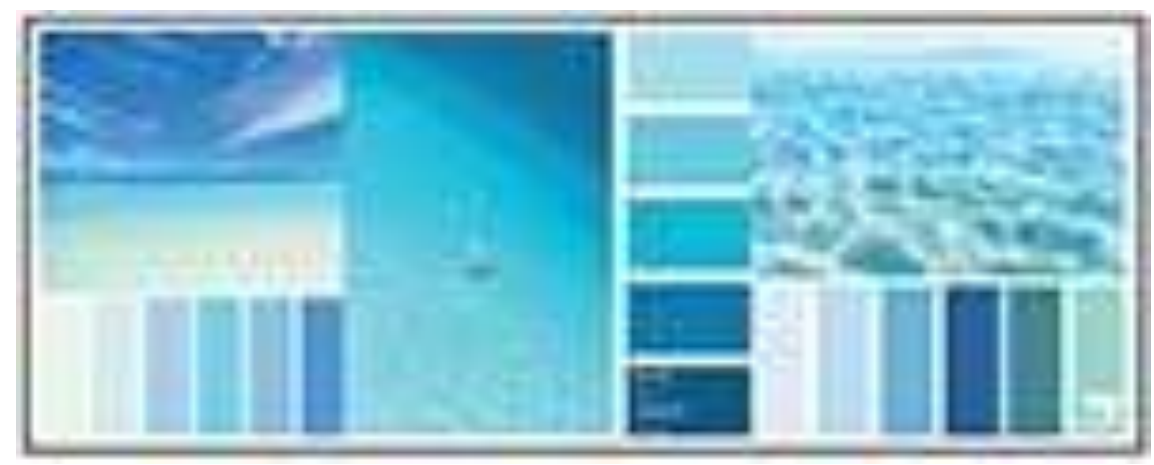

Gambar.6 studi warna.

(Sumber : berbagai sumber)

Masih tetap mengunakan skema warna analogus dengan pemilihan warna biru dengan masih tetap mempertahankan dan mengadopsi dari nuansa alam kota Garut. Bukan hanya alam pegunungan yang dimiliki kota Garut tetapi wisata pantai pun di miliki kota Garut. Selain itu warna biru memberikan kesan modern, dan santai yang ingin ditawarkan dari studi color mood yang dilakukan.

\section{Logotype}

Dari beberapa sumber referensi dalam perancangan logotype Portal Pesona Garut memunculkan dua alternative seperti yang ditampilkan pada gambar. 


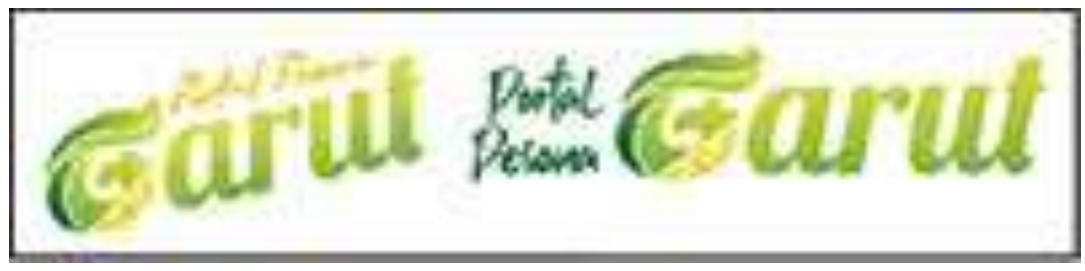

Gambar.7 studi logotype.

(Sumber : dokumentasi Tim)

Logotype Portal Pesona Garut terbagi menjadi dua bagian dalam keterbacaannya yaitu Portal Pesona dan Garut. Pemilihan logotype yang digunakan pada pemilihan logotype sebelah kanan dengan pertimbangan dari faktor keterbacaan yang lebih jelas. Pengunaan ornament batik pada huruf $\mathrm{G}$ menjadikan elemen batik menjadikan budaya yang tetap dibudidayakan di kota Garut.

\section{Typografi}

Pengunaan huruf dalam perancangan website sesuai dengan referensi yaitu dengan mengunakan huruf sans serif.

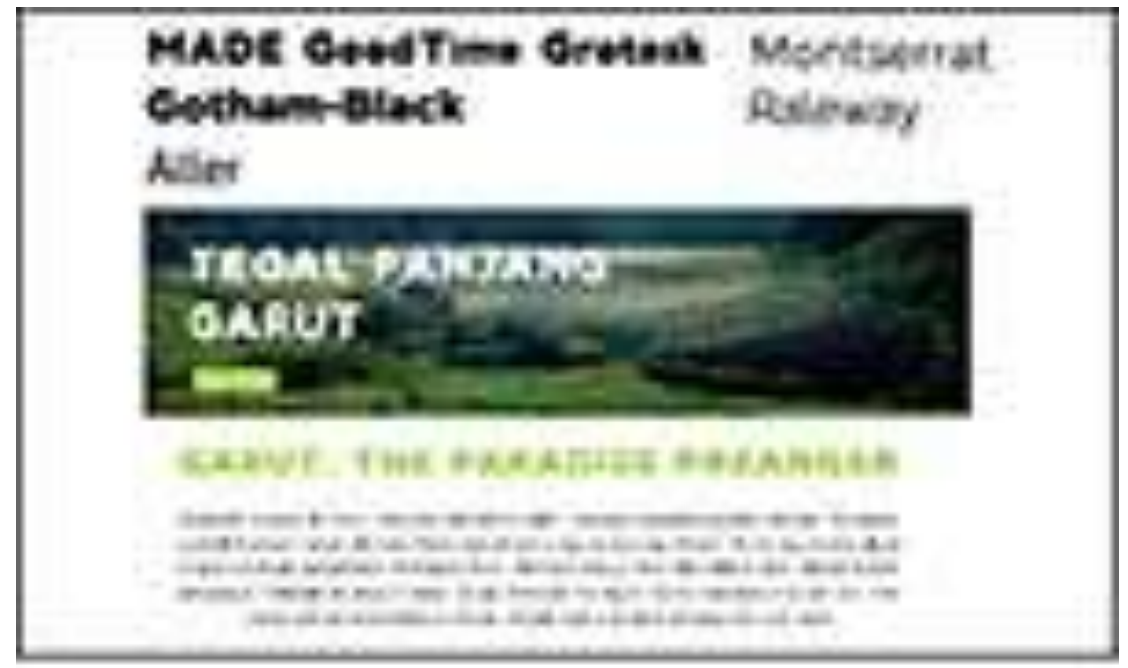

Gambar.7 studi typografi.

(Sumber : dokumentasi Tim)

Pengunaan huruf sans serif dalam perancangan website Portal Pesona Garut dibagi menjadi tiga kategori; Headline mengunakan jenis huruf Monstserrat Extra Bold, Subheadline: mengunkan jenis huruf Raleway Bold, sedangkan pada Bodytext mengunakan jenis huruf Raleway Regular.

\section{Ornament Estetis}

Beberapa sumber referensi telah membantu dalam perancangan ornament estetis, terlihat pada gambar. 8 alternative ornament estetis. 


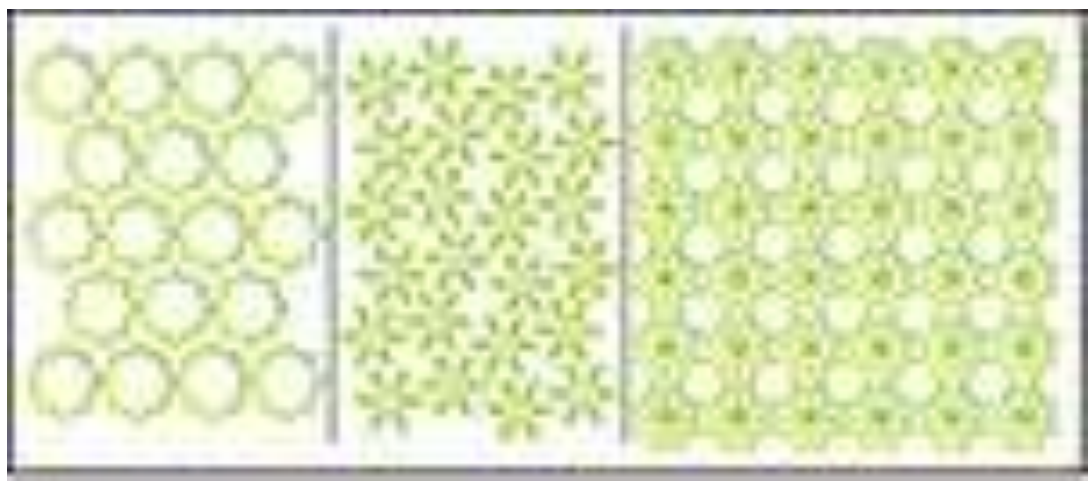

Gambar.8 studi ornament estetis.

(Sumber : dokumentasi Tim)

Perancangan ornament estetis tetap terfokus dengan pendekatan untuk menghasilkan citra nuansa islami. Pengambilan bentuk dasar yang masih tetap sama tetapi dengan cara mengkombinasikan yang berbeda - beda, sehingga dapat menghasilkan variasi bentuk yang berbeda dengan tetap berorientasi pada nilai islami.

\section{Icon}

Beberapa dalam perancangan icon, terlihat pada gambar. 9

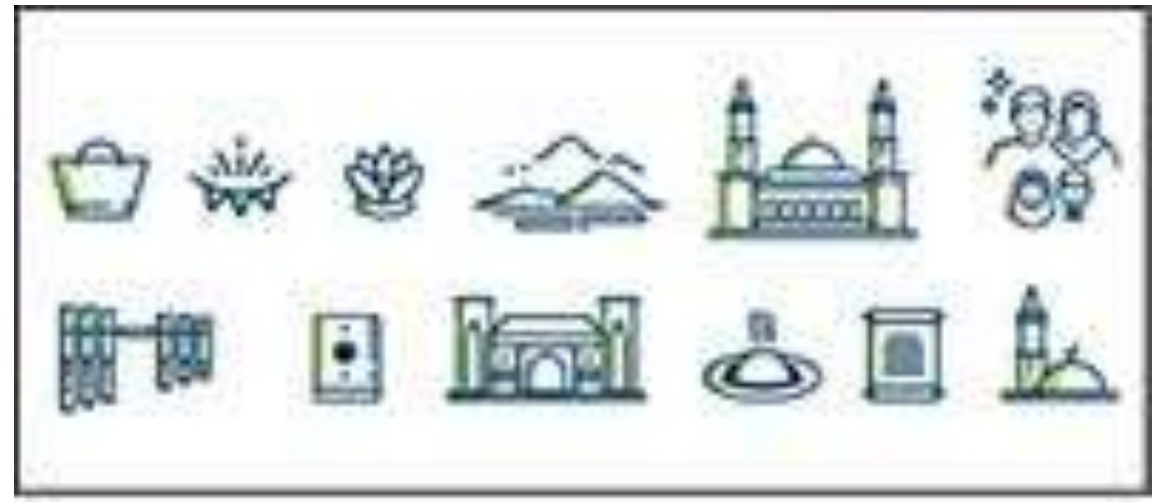

Gambar.9 studi icon.

(Sumber : dokumentasi Tim)

Perancangan icon pada kebutuhan website Portal Pesona Garut sangat dibutuhkan dengan pertimbangan banyaknya kategorisasi conten yang terdapat didalam portal tersebut. Pengunaan icon yang komunikatif menjadi sangat penting dalam menginformasikan sesuatu kepada user. Perancangan icon mengunakan pendekatan terhadap objek - objek yang keberadaannya cukup dekat dengan masyarakat pada umumnya. Dengan mengunakan metode pengerjaan yang berorientasi pada linening diharapkan dapat membuat kesan lebih simple dan ringan dalam menerapkannya pada website Portal Pesona Garut.

\section{Implementasi elemen visual pada website Portal Pesona Garut.}

Penerapan elemen visual tidak mempunyai banyak kendala dalam menyatukan dari setiap elemen visual yang telah sebelumnya dirancang. Perpaduan dalam setiap elemen visual dapat memberikan nilai kesatuan yang pada akhirnya secara holistic memberikan 
nuansa islami dan casual sebagaimana yang telah dikonsepkan dalam solusi yang ditawarkan.

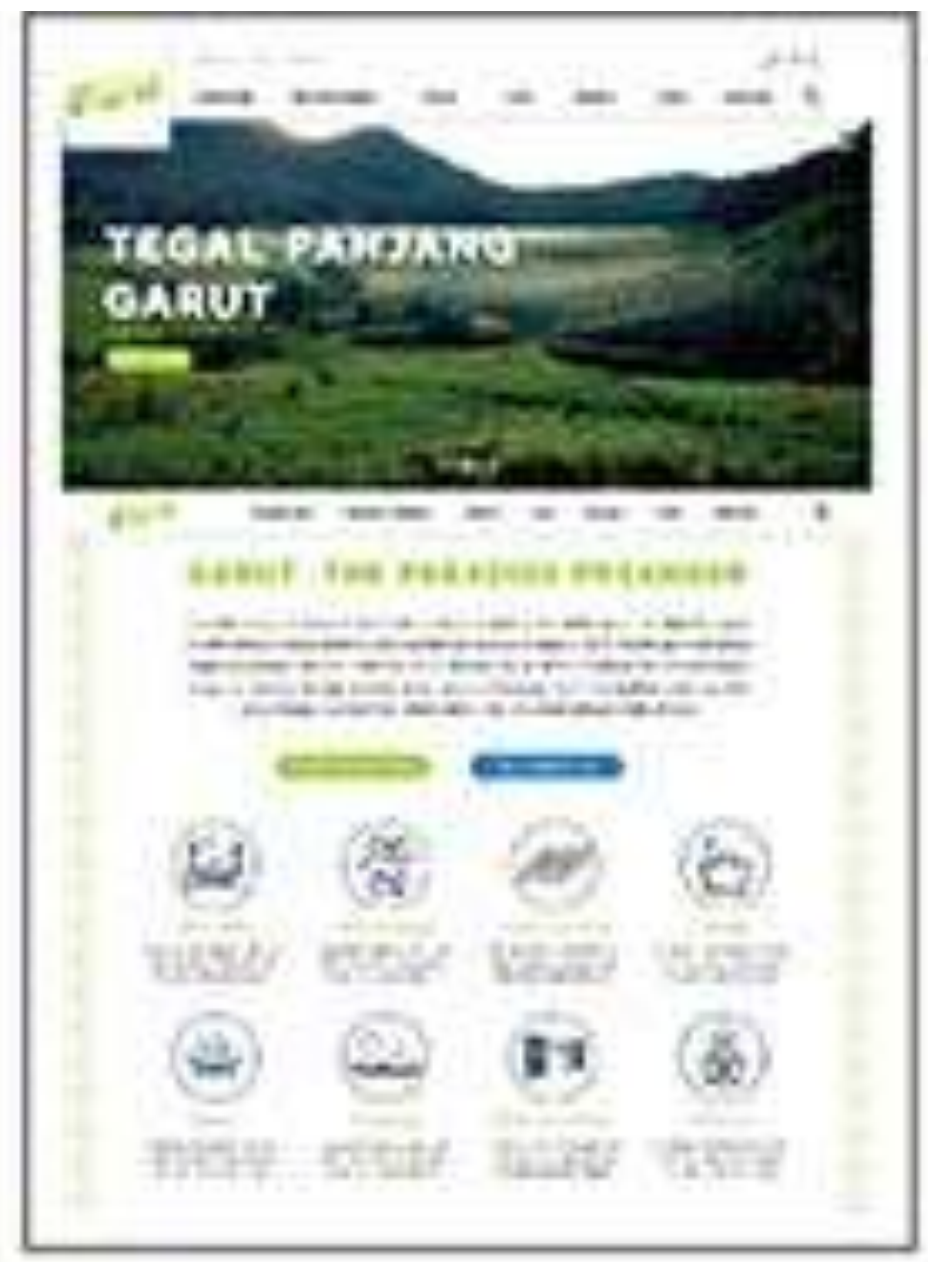

Gambar.10 hasil perancangan website Portal Pesona Garut

(Sumber : dokumentasi Tim)

\section{KESIMPULAN DAN SARAN}

Kegiatan pengabdian masyarakat diawali dengan pembuatan website Portal Pesona Garut yang telah dilakukan pada tahap sebelumnya. Optimalisasi tampilan website Portal Pesona Garut dilakukan dengan mengedepankan pendekatan yang bersifat kultural. Perancangan tampilan menjadi hal yang sangat sensitif maka dari itu hal tersebut dilakukan agar dapat lebih tepat dalam merepresentasikan sebuah citra daerah/kultur tertentu untuk diinformasikan kepada calon wisatawan. Diharapkan semua elemen dapat terus mendukung dari keberadaan website Portal Pesona Garut dan menjadikan sebuah peluang untuk menjadi portal wisata halal tersebut percontohan bagi daerah lainnya dan berpeluang untuk ikut dalam ajang kompetisi halal tourism website. 


\section{DAFTAR PUSTAKA}

1. Galitz, W. (2007). The Essential Guide to User Interface Design: An Introduction to GUI Design Principles and Techniques. Indianapolis: Wiley Publishing.

2. Garrett, J. (2011). The Elements of User Experience : User-Centered Design for the Web and Beyond. Berkeley: New Riders.

3. Kusrianto, A. (2009). Pengantar Desain Komunikasi Visual. Yogyakarta: Penerbit Andi. 